\title{
Formulation and evaluation, comparison of herbal hair dye with marketed formulation
}

\author{
S. Sri Bhuvaneswari , T. Prabha, S. Sameema Begum, T. Sivakuamr, P. Saranraj*, V. Manivannan* and B. Ashok Kumar** \\ Department of Pharmaceutical Biotechnology, Nandha College of Pharmacy, Erode-638052, Tamil Nadu, India \\ *Nandha College of Physiotherapy, Erode-638052, Tamilnadu, India \\ **Nandha Engineering College, Erode-638052, Tamilnadu, India
}

\section{Article Info}

Article history

Received 17 October 2021

Revised 5 December 2021

Accepted 8 December 2021

Published Online 30 December 2021

Keywords

Herbal hair dye

Indigo

Henna

Synthetic hair dye

\begin{abstract}
Herbal products are being preferred due to the advantages in contrast to the synthetic one which has adverse effect on human health because of harsh chemicals like paraphenylene diamine. The word "Herbal" is a symbol of safety. Thus, our current research was aimed to prepare the herbal hair dye using the herbal extract from the diverse powders of herbals such as, Lawsonia inermis, Aloe vera, Phyllanthus emblica, Thea sinensis, Trigonella foenum-graecum, Eclipta alba, Acacia catechu, Indigofera tinctoria, and Terminalia bellirica. Three different formulations were made by mixing the varying proportion of extract from henna and indigo at the ratio of 1:0, 2:1 and 1:2, respectively. These different combinations of formulation were further evaluated for dyeing effect on unpigmented hair. The results with F3 formulation contain the extract of henna and indigo at a ratio of 1:2 that gave dark brown to black colour to hair, resembling natural hair colour. From our pharmaceutical evaluation studies, the formulation exhibited the better dyeing effect, free from skin irritation, free of obnoxious odour and great retention capacity, benefits of promotion of hair growth, suitable for all age group and ecofriendly on comparison with marketed synthetic dye formulation.
\end{abstract}

\section{Introduction}

Colors derived from plants and animals without any chemical processing are known as natural dyes. Herbal remedies that contain phytochemicals derived from a variety of botanical sources, which affect and supply nutrition for good skin and hair (Nupur, 2021; Sumit et al., 2012). Hairs are an important part of human beauty. People are using herbs for cleaning, beautifying and hair growth since the ancient era (Dubey et al., 2004). There are a variety of medicinal plants with possible hair effects that have been used for centuries around the world and are now incorporated into dye formulations. These medicinal herbs can be utilised as extracts, powdered extracts, crude extracts, or derivatives (Latha et al., 2021; Vijayalakshmi et al., 2018; Gangurde et al., 2013).

Researchers have been searching for novel medications in nature since the dawn of mankind (Chanchal et al., 2017). Plant products have been used in phytomedicine from the beginning of time. Around $80 \%$ of the world's population uses traditional medicines based on plant extracts for primary healthcare. Almost $90 \%$ of prescriptions in traditional systems of Unani, Ayurveda, Homeopathy, and Siddha were based on drugs derived from plants (Fathima et al., 2011; Amsa et al., 2014). Plant-based medicines are readily available, less priced, safe, and effective, with little side effects. Saffron and indigo were also utilised by the ancients to give the dye a desired function

Corresponding author: Mrs. S. Sri Bhuvaneswari Associate Professor, Nandha College of Pharmacy, Erode-638052. Tamilnadu, India

E-mail: s.sribhu@gmail.com

Tel.: +91-9629445695

Copyright (c) 2021 Ukaaz Publications. All rights reserved.

Email: ukaaz@yahoo.com; Website: www.ukaazpublications.com
(Kumar et al., 2016). The colour that is currently available contains ingredients that are amino compounds (4- amino-2-hydroxytoluene and m-aminophenol). Colorants such as titanium dioxide and iron oxide are also commonly employed in the process (Mallya et al., 2015). Prolonged use of such dye-containing substances on natural hair has numerous negative consequences, including skin irritation, erythrema, hair loss or damage, and skin cancer (Nilani et al., 2010). Synthetic hair dyes contain harmful and hair-damaging chemicals such as paraphenylene diamine, ammonia, and paraben. Many people are switching to natural hair colouring methods as they become more aware of their side effects (Prabhu et al., 2012). Natural hair dyes are a safer alternative because they are made up of plantbased ingredients rather as harsh chemicals (Pal et al., 2018).

Natural hair dye gives our hair a natural black colour without harming it. Even after repeated colouring, our hair remains healthy as a result of this. Because traditional hair colouring procedures based on natural or synthetic colourants have limitations, this study aimed to develop a hair dye based on crude medicines with good colouring properties that is both safe and ready to use (Mahale et al., 2000; Kadambari et al., 2009).

\section{Materials and Methods}

\subsection{Plant source}

The powder of henna (Lawsonia inermis), indico (Indigofera tinctoria), aloe (Aloe vera), amla (Phyllanthus emblica), tea (Thea sinensis), fenugreek (Trigonella foenum-graecum), bhringraj (Eclipta alba), black catechu (Acacia catechu), myrobalan (Terminalia chebula), were procured from Ayurvedic shop in Erode, Tamilnadu, India. 
Description of the ingredients of the herbal hair dye (Gediya et al., 2001; Chaudhary et al., 2010; Pandey et al.,2010; Kaur et al., 2002)

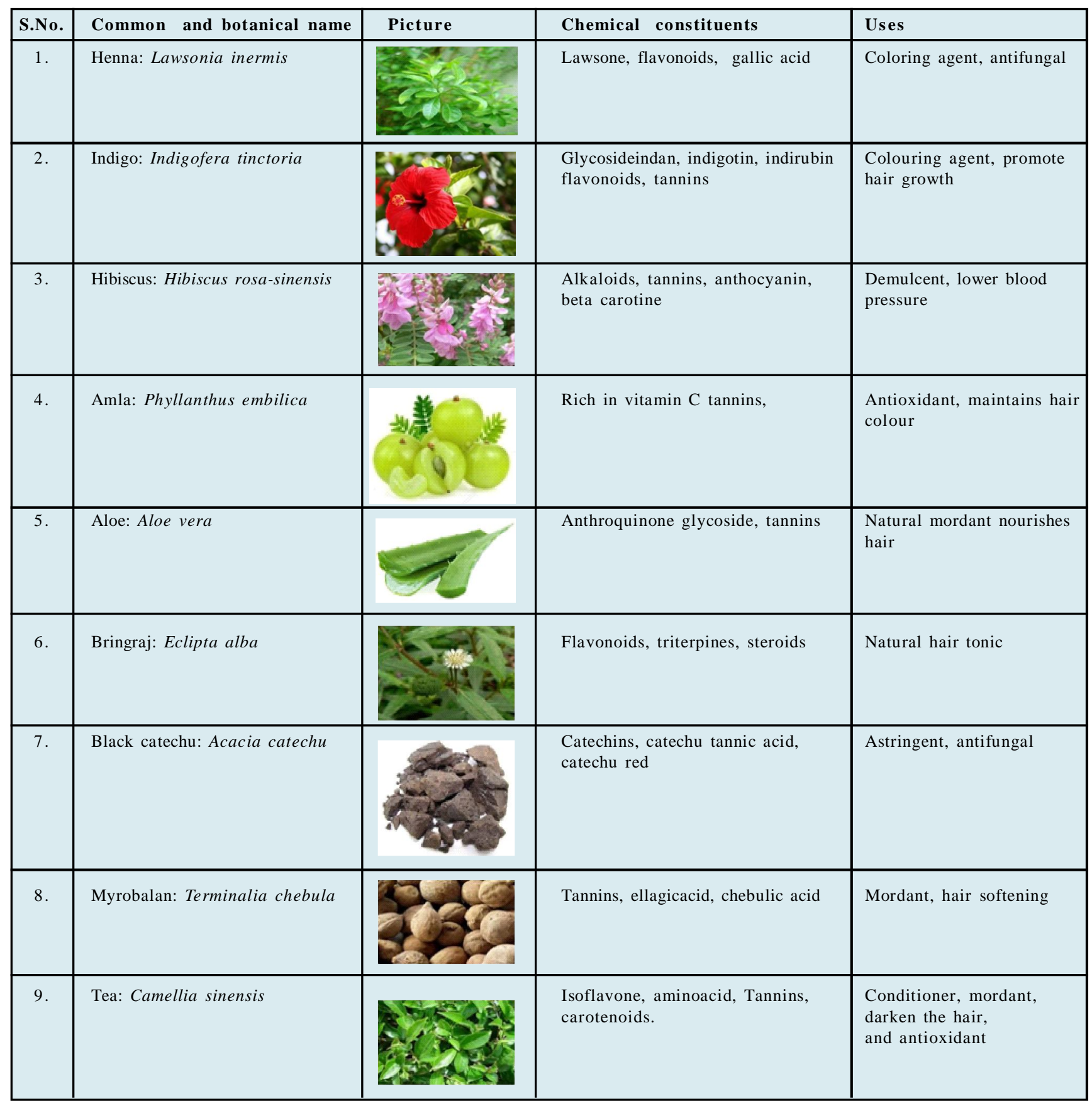

\subsection{Preparation of herbal extracts}

$100 \mathrm{gm}$ each of all the herbal powder was taken separately and boiled with $100 \mathrm{ml}$ of distilled water for $1 \mathrm{~h}$ and the extract was filtered and evaporated to dryness.

\subsection{Phytochemical evaluation}

The prepared herbal extract was subjected to phytochemical screening to reveal the various phytoconstituents as carbohydrates, lipids, alkaloids and sugars, etc. (Bhawana et al., 2021; Kokate et al., 2008; Wallis et al., 2002., Malik et al., 2020). The extract was dissolved individually in $5 \mathrm{ml}$ of water and filtered; the filtrates were used to carry out the chemical test and the result was shown in Table 1.

\subsection{Formulation of herbal hair dye}

All the dried herbal extracts were taken as per the quantities mentioned in Table 2 and it was continuously mixed with water to prepare uniform pastes. 


\subsection{Evaluation of the herbal hair dye}

The formulated herbal hair dye was evaluated for various parameters, such as organoleptic, physicochemical, rheological and phytochemical evaluation.

\subsubsection{Organoleptic evaluation}

Organoleptic characteristics for various sensory characters like color, taste, odour, and special features, like touch, texture and appearance, etc., was carefully identified (Evans et al., 1997; Padmini et al., 2013) and was illustrated in Table 3.

\subsubsection{Physicochemical evaluation}

The physical and chemical features of the herbal hair dye were evaluated to determine the $\mathrm{pH}$, moisture content, and ash value (Kokate et al., 1994; Meenaprabha et al., 2021; Sagar et al., 2005; Singh et al., 2020). All these findings are mention in Table 4.

i. pH: The $\mathrm{pH}$ of formulated herbal hair dye was determined using $\mathrm{pH}$ meter.

ii. Moisture content: A method commonly used for moisture contant determination is the loss on drying method or LOD. The crude drugs heated at $105^{\circ} \mathrm{C}$ to constant weight and calculate the total loss of weight.

iii. Total ash value: The $2 \mathrm{gm}$ of sample was taken in a silica crucible then ignited by gradually increasing the heat to $400^{\circ} \mathrm{C}$ until it appeared white indicating absence of carbon. It is then cooled in a desiccator and total ash of air dried material is calculated.

\subsubsection{Rheological evaluation}

The parameters like untapped or bulk density, tapped density, the angle of repose, Hausner's ratio, and carr's index were observed (Gennaro et al., 2000; Sneha et al., 2014; Kokare et al., 2014; Puranik et al., 2012; Taha et al., 2019 ) and it was shown in Table 4.

i. Angle of Repose: Angle of repose was determined using the funnel to estimate the flow behavior of the sample and it was determined by using the formula;

Tan $\alpha=H / R$

where, $\alpha=$ angle of repose; $\mathrm{H}=$ height of the pile of powder; $\mathrm{R}=$ radius of the pile of powder.

ii. Determination of bulk density and tapped density: Bulk density and tapped density was determined by placing the cylinder containing sample (W1) in bulk density apparatus and the volume was noted as V1 ( $\mathrm{ml})$, then the apparatus adjusted for 100 tapping and operated. The volume occupied by the powder as V2 $(\mathrm{ml})$ was recorded.

$$
\begin{aligned}
& \text { Bulk Density = Mass } / \text { Bulk volume }=\mathrm{W} 1 / \mathrm{V} 1 \mathrm{~g} / \mathrm{ml} \\
& \text { Tapped Density = Mass/Tapped volume }=\mathrm{W} 1 / \mathrm{V} 2 \mathrm{~g} / \mathrm{ml}
\end{aligned}
$$

iii. Hausner's ratio: Hausner's ratio is the ease of index of powder flow and calculated by using following formula:

Hausner's ratio $=$ Tap density/Bulk density

iv. Carr's index: Per cent compressibility of blend was determined by Carr's compressibility index, which was calculated by using following formula:

Carr's index $=$ Tap density - Bulk density $\times 100$ Tap density

\subsection{Skin sensitivity test}

Because herbal hair dyes should not cause skin sensitization or irritation when applied to hair, the samples were subjected to a skin irritation research. The skin irritation was calculated using the Draize modified scoring technique every $24 \mathrm{~h}$ for seven days after the colours were applied, and the skin irritation investigations were conducted on healthy rabbits (Regupathi et al., 2016). The experimental protocol was approved by Institutional Animal Ethic Committee. (688/2/CPCSEA). The rabbits' dorsal surface $\left(50 \mathrm{~cm}^{2}\right)$ was cleaned and the hair was shaved away. With rectified spirit, the skin was washed. Samples of herbal hair dye were applied to the skin. The skin was monitored for six days to check the skin irritation, redness, and edoema production. Table 4 shows the results of testing to look for indicators of irritation.

\subsection{Stability test}

Stability testing of the prepared formulation was performed by storing it at different temperature conditions for the time period of one month. The packed formulation were stored at different temperature conditions, viz., room temperature and $35^{\circ} \mathrm{C}$ and were evaluated for the physical parameters. The prepared dye formulations were evaluated for the physical parameters like colour, odour, pH, texture, and smoothness (Arora et al., 2019).

\subsection{Studies on dyeing effect}

Each formulated dye (F1-F3) was applied to the gray hair which was collected from human volunteers. The colouring effect of formulated dye was observed After 30 and $60 \mathrm{~min}$. The hairs were washed with herbal shampoo and dried at sun light. The fastness property and dyeing effect on gray hair was observed and the results were shown in Table 5 .

\subsection{Comparison of dyeing effect with marketed brand}

The dyeing effect of formulated dye was compared with synthetic hair dye marketed as black henna was used as standard. The colour comparison was noted in different time duration such as 30 and 60 min and was reflected in Table 5.

\section{Results}

The Table 1 highlight of various phytoconstituents present in the herbal formulation. Henna and Indigo contain a pigment used as a colouring agent, tannin present in the tea, and aloe used as a mordant and it enhance colour intensity of hair, in addition to it promote hair growth and act as emollient. Amla and Hibiscus contain vitamins, aminoacids, and flavonoids, which together form a powerful antioxidant, antidandruff and it is beneficial for smooth and silky hair, whereas, Hibiscus used as good conditioner.

\subsection{Evaluation of the herbal hair dye}

The formulated herbal hair dye was evaluated for various parameters, such as, organoleptic, physicochemical, rheological, and phytochemical evaluation.

The preparation of herbal hair dye Henna and Indigo were chosen for natural colorant and it was brownish black, blackish brown in colour and appears as a smooth powder with pleasant odour. 
Table 1: Phytochemical evaluation of herbal extract

\begin{tabular}{|c|c|c|c|c|c|c|c|c|c|c|}
\hline S.No. & Phytoconstituents & Henna & Indigo & Hibiscus & Amla & Aloe & Bhringraj & Black catechu & Myrobalon & Tea \\
\hline 1 & Alkaloids & - & - & + & + & - & + & + & - & + \\
\hline 2 & Glycosides & + & - & + & - & + & - & - & + & - \\
\hline 3 & Tannins & + & + & - & + & + & - & + & + & + \\
\hline 4 & Flavonoids & + & + & + & + & - & - & + & - & + \\
\hline 5 & Terpenoids & + & + & + & - & - & + & - & + & - \\
\hline 6 & Carbohydrates & + & + & + & + & + & + & - & + & + \\
\hline 7 & Aminoacids & - & - & + & + & - & + & - & - & + \\
\hline 8 & Carotinoids & + & - & + & - & - & - & - & - & + \\
\hline 9 & Saponins & - & - & + & - & + & + & - & + & - \\
\hline
\end{tabular}

Table 2: Formulation composition of herbal hair dye

\begin{tabular}{|c|l|c|c|c|}
\hline S.No. & Ingredient & Formulation (F1) & Formulation (F2) & Formulation (F3) \\
\hline 1 & Henna & $35 \mathrm{~g}$ & $20 \mathrm{~g}$ & $10 \mathrm{~g}$ \\
2 & Indigo & - & $10 \mathrm{~g}$ & $20 \mathrm{~g}$ \\
3 & Hibiscus & $5 \mathrm{~g}$ & $5 \mathrm{~g}$ & $5 \mathrm{~g}$ \\
4 & Amla & $2 \mathrm{~g}$ & $2 \mathrm{~g}$ & $2 \mathrm{~g}$ \\
5 & Aloe & $2 \mathrm{~g}$ & $2 \mathrm{~g}$ & $2 \mathrm{~g}$ \\
6 & Bhringraj & $2 \mathrm{~g}$ & $2 \mathrm{~g}$ & $2 \mathrm{~g}$ \\
7 & Black catechu & - & $5 \mathrm{~g}$ & $5 \mathrm{~g}$ \\
8 & Myrobalan & - & $2 \mathrm{~g}$ & $2 \mathrm{~g}$ \\
9 & Tea & $2 \mathrm{~g}$ & $2 \mathrm{~g}$ & $2 \mathrm{~g}$ \\
\hline
\end{tabular}

Table 3: Organoleptic evaluation of herbal dye

\begin{tabular}{|c|l|l|l|l|}
\hline S.No. & Parameters & \multicolumn{1}{|c|}{ F1 } & \multicolumn{1}{|c|}{ F2 } & \multicolumn{1}{|c|}{ F3 } \\
\hline 1 & Colour & Reddish brown & Brownish black & Blackish brown \\
$\mathbf{2}$ & Odour & Characteristic & Characteristic & Characteristic \\
3 & Texture & Smooth & Smooth & Smooth \\
4 & Appearance & Powder & Powder & Powder \\
\hline
\end{tabular}

Table 4: Physicochemical evaluation parameters

\begin{tabular}{|c|l|l|l|l|}
\hline S.No. & Parameters & F1 & F2 & F3 \\
\hline 1 & Bulk density & 0.32 & 0.31 & 0.30 \\
2 & Tapped density & 0.51 & 0.50 & 0.45 \\
3 & Angle of repose & 27.55 & 27.65 & 26.54 \\
4 & Corr's index & 1.22 & 1.20 & 1.10 \\
5 & Hausner's ratio & 1.24 & 1.36 & 1.30 \\
6 & PH & 6.7 & 6.9 & 6.5 \\
7 & LOD & 1.7 & 1.9 & 1.5 \\
8 & Ash value & 0.18 & 0.16 & 0.17 \\
9 & Irritancy test & Nil & Nil & Nil \\
\hline
\end{tabular}


Table 5: Study on dyeing effect on human hair with herbal hair dye

\begin{tabular}{|l|c|c|c|c|c|c|}
\hline \multirow{2}{*}{ Dyeing effect } & \multicolumn{3}{|c|}{ After 30 min } & \multicolumn{3}{c|}{ After 60 min } \\
\cline { 2 - 7 } & F1 & F2 & F3 & F1 & F2 & F3 \\
\hline Appearance of hair & No damage & No damage & No damage & No damage & No damage & No damage \\
Colour of the hair & Orange & Red & Reddish brown & Brown & Brownish black & black \\
\hline
\end{tabular}

Table 6: Study on dyeing effect on human hair with marketed brand

\begin{tabular}{|c|l|c|c|}
\hline S.No. & Dyeing effect & After 30 min & After 60 min \\
\hline 1 & Appearance of hair & Hair damage & Cortex damage \\
2 & Colour of the hair & Black & Dark black \\
\hline
\end{tabular}

The Table 4 mentioned that the low moisture content was found that will enhance the flow property and prevents the microbial contamination during storage, the ash value was found to be 0.17 and it was nominal. Indicating the presence of inorganic radicals in significant amount ( $\mathrm{pH}$ 6.5), which was found to neutral and it was suitable of different scalp types. However, the skin irritation study result showed that all the formulations (F1-F3) were free from allergic reactions to rabbit skin, no itching, redness, and rashes have been observed for all the formulations.

\subsection{Stability test}

Stability test was performed for approximately one month period at different temperature to observe the changes in its colour, odour, texture, appearance, $\mathrm{pH}$. The formulations were found to be stable during this period. Thus, the result conclude that the prepared formulations were could be easily stored and used at any stability conditions. Since it is a natural herbal based formulation, i.e., it is free from harsh chemical, preservatives and artificial colors. Moreover, the moisture content was low and there are minimal possibilities of the deterioration of the formulation, this leads to an increased shelf life due to goodness of natural ingredients.

From the results shown in above Table 5, the varying colour intensity was observed with different formulation. The formulation was prepared with varying proportion of Henna and Indigo along with above mentioned powder and helps to create various colour shades. Good dyeing effect was obtained with formulation (F3) had the ratio of Henna and Indigo (1:2), that gave black colour to the hair. The glimpse was shown in Figure 1.

Thecolour intensity was compared with that of marketed product which contains PPD in their formulation and the result shows good deying effect within $30 \mathrm{~min}$,but it cause hair damage and skin irritation because of harsh chemicals (Figure 2).

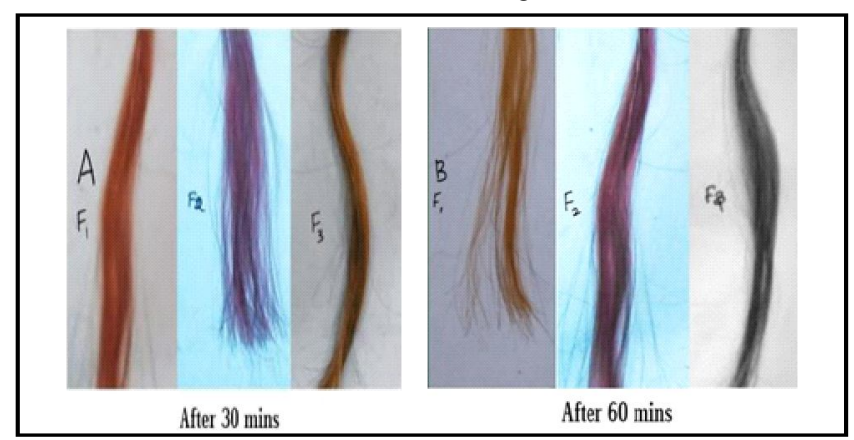

Figure 1: Dyeing effect of herbal hair dye on human gray hair.

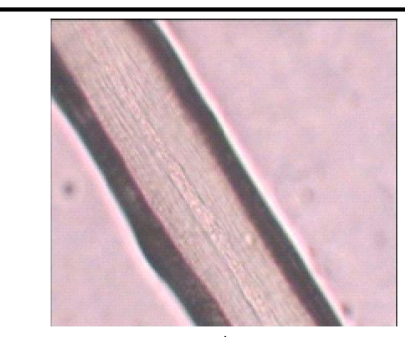

A

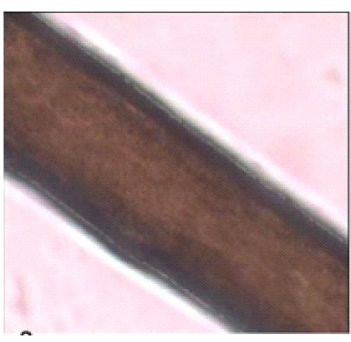

$\mathrm{C}$

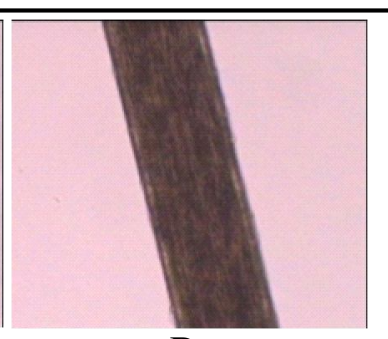

B

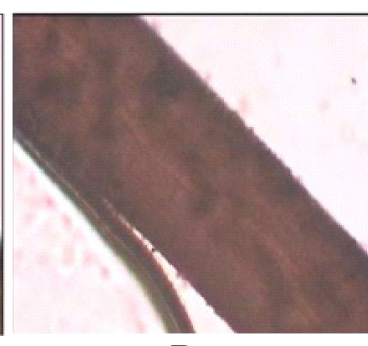

$\mathrm{D}$
Figure 2: Comparison of dyeing effect of herbal hair dye with marketed brand on human gray hair.

A. Microscopic features of gray hair treated with herbal hair dye showing no damaged cortex after $30 \mathrm{~min}$.

B. Microscopic features of gray hair treated with herbal hair dye showing no damaged cortex after $30 \mathrm{~min}$.

C. Microscopic features of gray hair treated with marketed brand showing no damaged cortex after $30 \mathrm{~min}$.

D. Microscopic features of grey hair treated with marketed brand showing damaged cortex after $60 \mathrm{~min}$.

\section{Discussion}

The herbal hair color that has been developed has all of the benefits of natural components. Aside from acting as a hair colour, this composition also functions as a hair growth booster, hair nourisher, conditioner and antidandruff agent owing to the right combination of natural herbs. Henna, the basic powder, serves as a worldwide hair color, as it is utilised for its dyeing capabilities all over the world. It also helps to remove excess sebum from the scalp while also conditioning the hair. Bhringraj helps to improve blood circulation at the base of the hair (Rashmi et al., 2018). Amla is high in vitamins $\mathrm{A}, \mathrm{C}, \mathrm{D}$, and $\mathrm{K}$ that combine to make a potent 
antioxidant. This antioxidant is likely the main factor your hair requires to remove oil accumulation from the hair, clear pores, kill disease bacteria, and stimulate hair growth. Hair fall, flaking, and grey hair may all be readily controlled by utilising hibiscus flower juice on a routine basis. Amla's high vitamin $\mathrm{C}$ content aims to mitigate early gray hair. It is an excellent hair booster and dandruff cure. Complementary formulations of carotenoids, flavonoids, and tannins are included in the herbal hair color composition, which assist to the colouring impact on human hair while also protecting it from photodamage. The leaves of Camellia sinensis and Hibiscus rosa-sinensis are a useful source of raw material for natural colouring because they are abundant in carotenoids, vitamins, flavonoids, and isoflavone. Aloe vera gel, which contains polysaccharide and moisture, serves as a natural mordant and also replenishes dry aged skin and hair, as well as preventing photodamage (Ashawat et al., 2008; Nilani and Saravanan, 2010).The efficacy data indicates that by adjusting the proportions of Henna and Indigo, an appropriate black colour for hair can be achieved. The colour intensity increases with repeated application of this formulation, and the colour lasts for around 20 days even after regular washing and exposure to sunlight. This effect can be due to the tannins in the formulation, which function as mordants and help to increase the dye's colour intensity.

\section{Conclusion}

According to our study findings, an appropriate black colour for hair may be obtained by varying the proportions of Henna and Indigo. Hair colourant absorption was greatest at a $\mathrm{pH}$ of $6.5-6.9$ and moreover, the use of the Henna and Indigo increased the colour intensity. This natural hair dye has the benefit of causing no skin damage, erythrema development, or edoema. It is made entirely of water soluble plant elements, and as a result, it has no unpleasant odour. As well, both the raw components and the finished product are $100 \%$ biodegradable and theses compositions are stable at room temperature. This natural herbal hair colourent is excellent for people of all age group and the formulation and processing methods are ecosustainable. Hence, we discovered the beneficial qualities of the natural herbal dye in our study; however, an additional research is needed to discover more helpful advantages of this herbal hair pack. Thus, the herbal formulations are in popular to satisfy the expectations of an expanding global market.

\section{Conflict of interest}

The authors declare no conflicts of interest relevant to this article.

\section{References}

Amsa, P.;Tamizharasi, S.;Jagadeeswaran, M. and Sivakumar, T. (2014). Preparation and solid state characterization of simvastatin nanosuspensions for enhanced solubility and dissolution. International Journal of Pharmacy and Pharmaceutical Sciences., 6(1):265269.

Arora, R.; Rathore, K.S. and Bharakatiya, M. (2019). Formulation and evaluation of herbal shampoo by extract of some plants. The Pharmaceutical and Chemical Journal., 6(4):74-80.

Ashawat, M.S.; Saraf, S. and Swarnlata, S. (2008). Comparative Sun Protection factor determination of fresh Aloe vera gel Vs marketed formulation. Indian J. Pharm. Educ. Res., 42(4):319-322.

Bhawana, S.; Shiv, C.S. and Afroz, A. (2021). Phytochemical screening and GC-MS analysis of Tamarindus indica L. (Angiosperms: Fabaceae). Ann. Phytomed., 10(1): 215-221.
Chanchal, D.K. and Yadav, S. (2017). A comprehensive review on herbal cosmetics. International Journal of Pharmaceutical Sciences and Research., 8(12):4930-4939.

Chaudhary, G; Goyal, S. and Poonia, P. (2010). Lawsonia inermis Linnaeus: A phytopharmacological review. International Journal of Pharmaceutical Sciences and Drug Research., 2:91-98.

Dubey, S.; Nema, N. and Nayak, S. (2004). Preparation and evaluation of herbal shampoo powder. Ancient science of life., 24(1):38-44

Evans, W.C. (1997). Treas and Evans Pharmacognosy. Harcourt Brace and Company Ltd., Sixteenth edition, New York, 128.

Fathima, A.; Varma, S.; Jagannath, P. and Akash, M.(2011). General review on herbal cosmetics. International Journal of Drug Formulation and Research, 2(5):140-65.

Gangurde, H.H.; Chordiya, M.A.; Tamizharasi, S. and Sivakumar, T. (2013). Statistical optimization of mesalamine pulsatile release $\mathrm{pH}$ dependent coated pellets for possible ileo-cecal targeting. Thai. Journal. of Pharmaceutical Sciences., 37(1):39-55.

Gediya, S.K.; Mistry, R.B.; Patel, U.K.;Blessy, M. and Jain, H.N. (2001).Herbal plants used as cosmetics. J. Nat. Prod. Plant. Resour., 1:24-32.

Gennaro, A.R. (2000). Remington: The Science and Practice of Pharmacy. Lipincott Williams and Wilkins, Mary land, Twentieth edition, pp:437.

Kadambari, T.; Neeraj, S. and Vijendra, S.(2009). Preparation and characterization of some polyherbal formulation for evaluation of hair colorant effects. Int. J. Pharm. Pharm Sci., 1(2):93-97.

Kaur, L.; Singh, A.P.; Singh, A.P. and Kaur, T.(2021). A review on herbal cosmetics. International Journal of Pharmaceutics and Drug Analysis., 9(3):196-01

Kokare, N.;Wadkar, K.A. and Kontawar, M.S. (2014).Review on standardization of herbal churna, Int. J.Res. Ayurveda Pharm., 5(3):397-401.

Kokate, C.K. (1994). Practical phramacognosy, Vallabh Prakashan.New Delhi, Forth edition, 123.

Kokate. C.K.; Purohit. A.P. and Gokhale, S.B. (2008). Pharmacognosy. 42nd ed.. Pune: India: NiraliPrakashan., 6:196-201.

Kumar, K.S.; Begum, A.; Shashidhar, B.; Meenu, M.; Mahender, C. and Vamsi, K.S.(2016).Formulation and evaluation of $100 \%$ herbal hair dye. International Journal of Advanced Research In Medical and Pharmaceutical Sciences.,1(2):1-5

Latha, S.; Selvamani, P. and Prabha, T. (2021). Pharmacological uses of the plants belonging to the genus commiphora. Cardiovasc. Hematol. Agents. Med. Chem., 19(2):101-117.

Mahale, G.; Sunanda, R.K. and Sakshi.(2000). Colour fastness of ecodyed cotton with marigold. Text Trends, 44(10):35-9.

Mallya, R.A. and Ravikumar P.A.(2015). Formulation and evaluation of natural hair colorants. Innovare. Acad. Sci., 7(3):347-349.

Meenaprabha, P.;Kamalakkannan, V.;Sambathkumar, R.; Janani, R. and Nithyanandham S.(2021). Formulation and evaluation of herbal hair dye. World Journal of Pharmaceutical Research., 10(5):1533-1544.

Malik, T.; Madan V.K. and Prakash, R. (2020). Herbs that heal: Floristic boon to the natural healthcare system. Ann. Phytomed., 9(2):6-14.

Nilani, P. and Saravanan, K.(2010). Formulation and evaluation of herbal hair dye: An ecofriendly process. J. Pharm. Sci. Res., 2(10):64856 . 
Nupur, M. (2021). Herbs that heal: Nature's pharmacy endowed remedies for better health. Ann. Phytomed., 10(1): 6-22.

Padmini, R. and Rashmi, M.(2013). Development and evaluation of a polyherbal topical formulation. JPR: Bio. Med. Rx: An. Int. J., 1(7):637-40.

Pal, R.S.; Pal, Y.; Rai, A.K.; Wal, P. and Wal, A.(2018).Synthesis and evaluation of herbal based hair dye. The Open Dermatology Journal., 12(1):9098 .

Pandey, S.;Meshya, N. and Viral, D.(2010). Herbs play an importantrole in the field of cosmetics. International Journal of Pharm. Tech. Research., 2:632-639.

Prabhu, K.H. and Bhute, A.S.(2012). Plant based natural dyes and mordants: a review. J. Nat. Prod. Plant Resour., 2(6):649-64.

Puranik, V.; Chauhan, D. K.; Mishra, V. and Rai, G. K. (2012). Effect of drying techniques on the physicochemical and bioactive components of selected medicinal herbs. Ann. Phytomed., 1(2):23-29.

Rashmi, S.P.; Yogendra, P.; Rai, A.K.; Pranay, W. and Ankita, W. (2018). Synthesis and evaluation of herbal based hair dye. The Open Dermatology Journal, 12:91-98.

Regupathi, T.; Chitra, K.; Ruckmani, K.; Lalitha, K.G. and Kumar, M. (2016) Formulation and evaluation of herbal hair gel for hair growth potential. Journal of Pharmacology and Clinical Research,
2(2):555581.

Sagar, R. and Dixit, V.K.(2005). Formulation and evaluation of herbal antidandruff shampoo. Nigerian Journal of Natural Products and Medicine, 9:55-60

Snehal, W. and Nitin, K.(2014). Preparation and evaluation of antidandruff polyherbal powder shampoo. Pharmacophore, 5(1):77-84.

Sumit, K.; Vivek, S.; Sujata, S. and Ashish, B.(2012). Herbal cosmetics: used for skin and hair. Inventi Rapid. Cosmeceuticals, 2012(4):1-7.

Singh S.; Bajpai, M. and Mishra P. (2020). Pharmacognostical evaluation of indigenous herbal drug: Carissa carandas Linn. fruit. Ann. of Phytomedicine., 9(2):263-70.

Taha, M.; Parveen, B.; Osman, B.; Abdoon, I. H.; Mohamed, M. S. and JA, W. (2019). In vitro profiling of plants used in Sudanese traditional medicine for antioxidant and antibreast cancer activities. Ann. Phytomed., 8(1):119-126.

Vijayalakshmi, A.; Sangeetha, S. and Ranjith, N. (2018). Formulation and evaluation of herbal shampoo. Asian Journal of Pharmaceutical and Clinical Research, 11(4):121-4.

Wallis, T.E.(2002). Text book of Pharmacognosy. 5th Ed.. New Delhi: CBS publishers and distributors, 123:(132)210-5.

S. Sri Bhuvaneswari, T. Prabha, S. Sameema Begum, T. Sivakumar, P. Saranraj, V. Manivannan and B. Ashok 